\title{
" الماعت فى مصر القديمة "
}

الشيماء حسين عبدالرازق- باحثة ماجستير

ملخص البحث:

يتحدث البحث عن الماعت ومفهومها عند المصري القديم ومدي تطبيقه لها في حياته ومدي تقديسه لها.

مفهوم الماعت:

هي كلمة من اللغة المصرية القديمة منسعة المعني فهي الحقيقة والعدالة والنظام و غير ها من الصفات الحميدة وهي أيضا واحدة من مجمع الآلهة المصرية ولذا فهي تصور محوري للحياة المصرية،

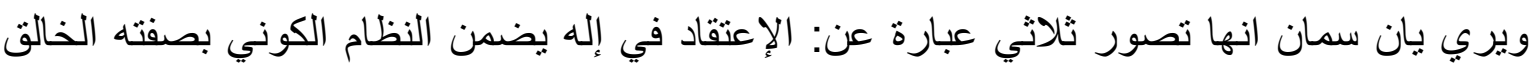

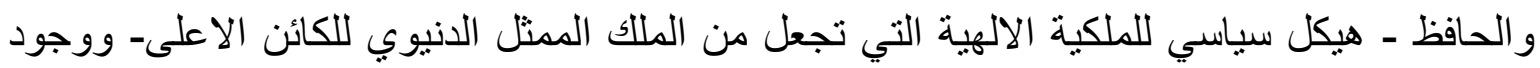

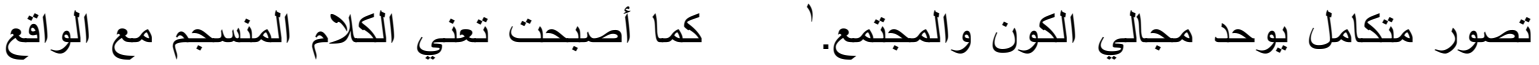
و العدالة اصبحت تعني الفعل المنسجم مع القوي المنظمة النشطة في الحفاظ على هذا النظام المتكامل وينحدر منها مفاهيم أكثر تخصصاً مثل القانون والعدالة والحقيقة, ويعتبر مفهوم الماعت من من أهم ابداعات الدولة القديمة اول مفهوم للعدالة كان في نهاية عصر الأسرة الخامسة في نقوش مقبرة "شسم نفر" في الجيزة نص يذكر (انهم فعلوا العدالة وتحدثوا إلى الماعت عندما جاءوا الى مدينتهم).

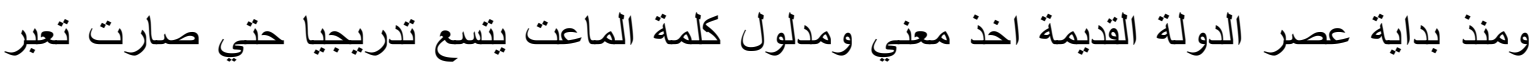
أيضاً في نظر عقول رجال الفال الفكر في الدولة القديمة عن معني النظام القومي اي النظام الاخلافي لثاني

\section{المعبودة ماعت:}

تعتبر الإلهة ماعت تجسيداً للقوانين, وعُبدت في مناطق عديدة على نطاق أوسع من أي معبودة

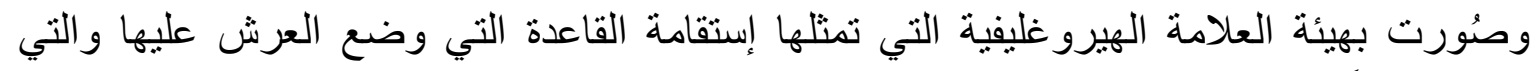

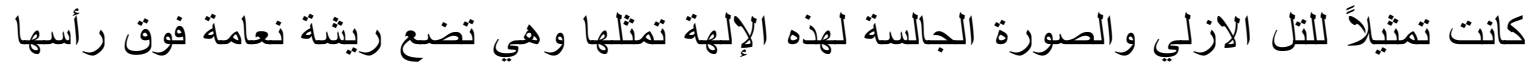
كامر أة واقفة او جالسة على عقب قدميها ترندي فوق راسها بريشة نعامة رمزاً لاسمها ل (الحقيقة

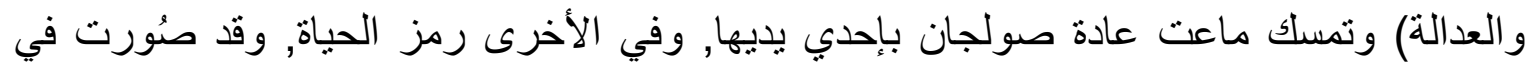

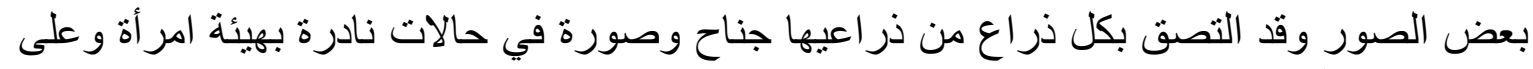

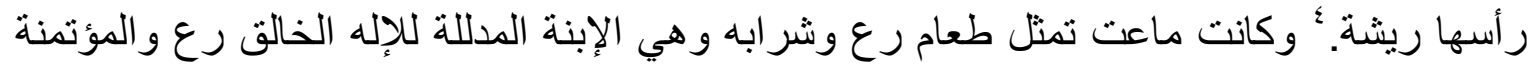

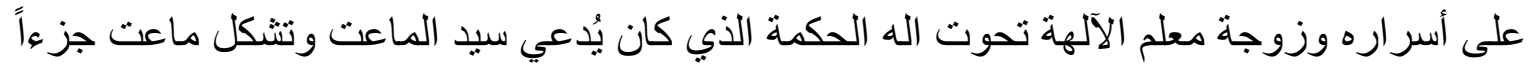

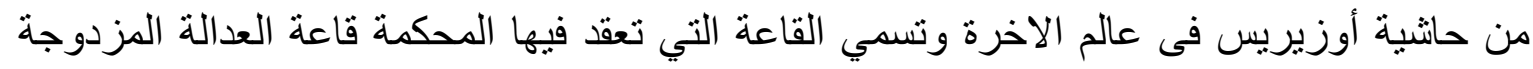
(قاعة ماعت المزدوجة),وتتخذ ريشة الماعت مكانها في إحدي كفتي الميزان مقابل قلب المبن الميت لغرض اختبار صدقه, وقد كانت الآلهة ماعت الهة تجريدية خالصة وكانت تحب اعب أن تغذي نفسها

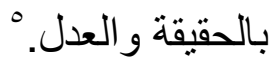




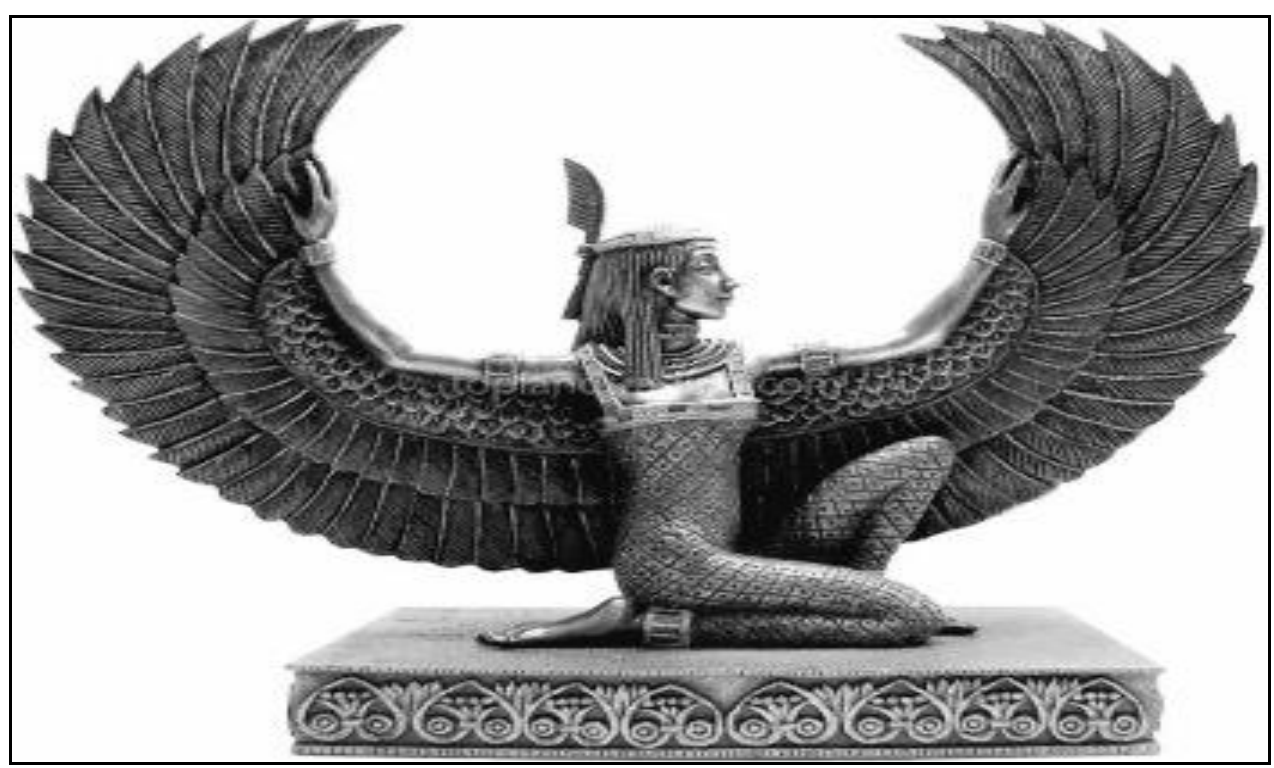

تمثال للمعبودة ماعت و هى جالسة وتفرد زر عيها وفوق راسها ريشة العدالة. نقلا عن: www// mact.com.

تطبيق نظام الماعت:

وطبقا لما ذكره بلوتارخ كان الملك يطلب من القضاة بألا يطيعوه إذا كانت أوامره اليهم ظالمة أي

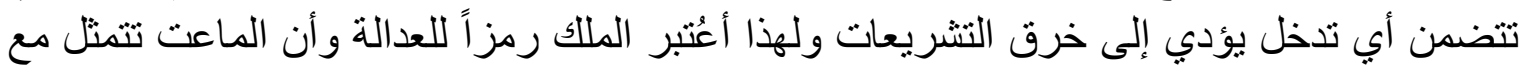

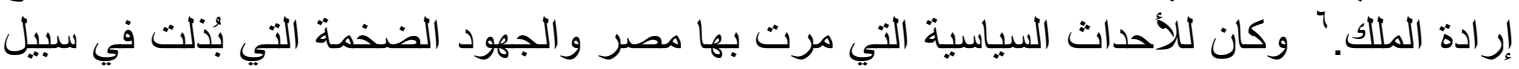

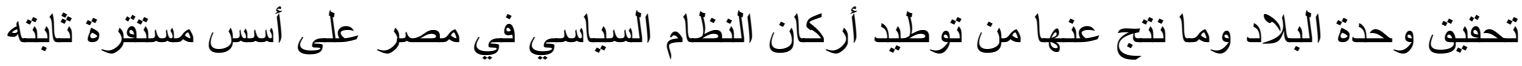

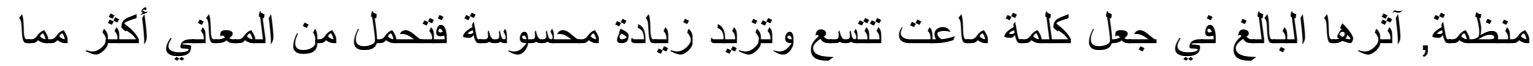

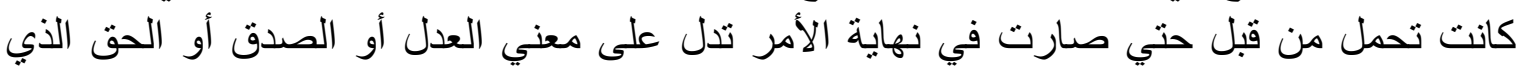
يجب أن يترسمه ويسير بمقتضاه الانسان.

تقديم الماعت: كما تقديم ماعت إلى أرباب المعابد حورس وحتحور و إيزيس وخنوم و أمون فحورس يفصل في الحقائق ويستجيب لدعوات من يتوجه اليه أما حتحور فهي ربة ماعت, وماعت ماعت هي كذللك

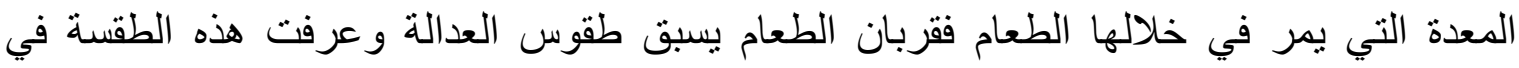
نصوص الدولة الوسطي وأول منظر لها يرجع إلى ما بعد العام الرابع من حكم تحتمس الثالث,

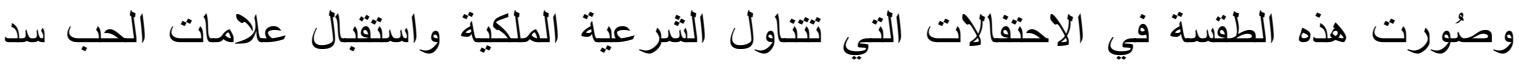

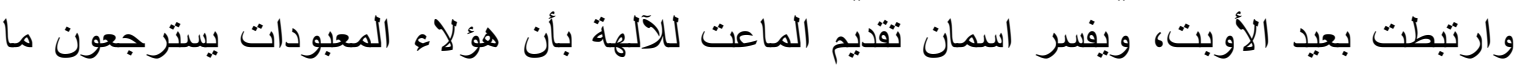

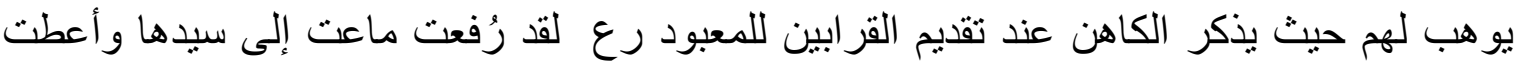

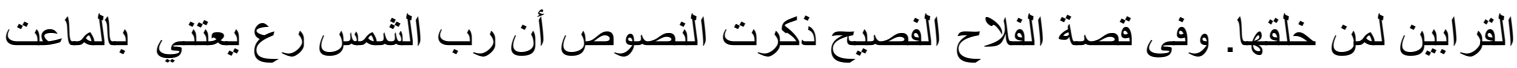

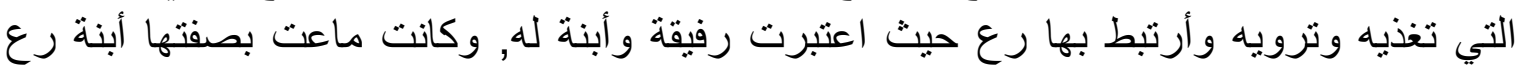

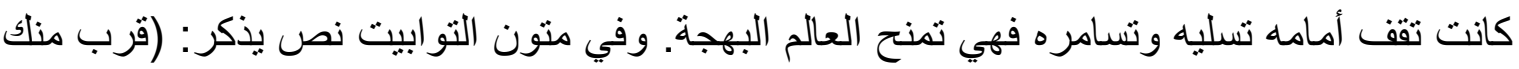

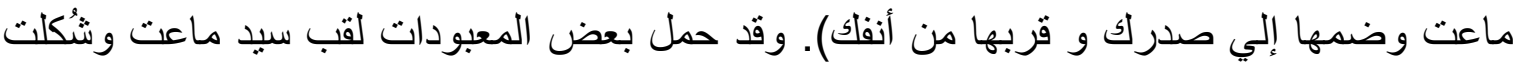
القاعدة التي يقف عليها بعضهم بهيئة علامة ماعت. و هناك منظر موجود بمعبد أبيدوس يمثل الملك ولك

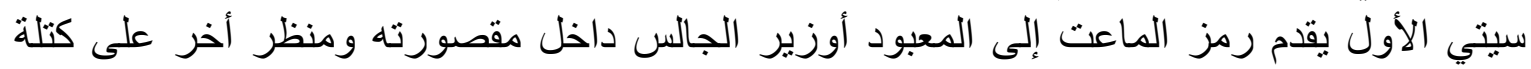

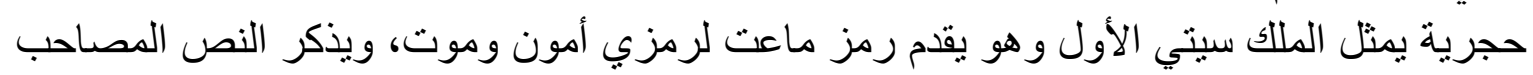


للمنظر:( خذ ابنتك الحبيية هي المريء الذي ينقل الطعام إلى معدتك, هي الجميلة ماعت التي يحيا

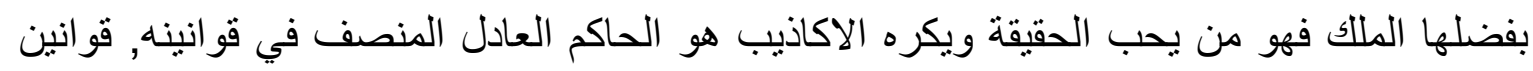

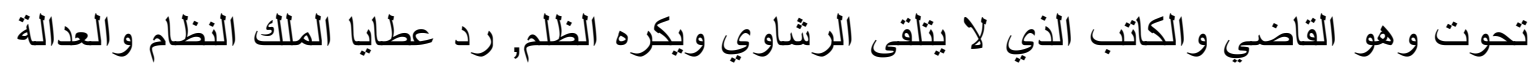
و الحقيقة ماعت في قلبك, أنت تحكم منل الآلهة والآلهات ) ماعت هي بالب وبكره لالنسبة للك القاض والكاتب الذي يبت في الحقائق هذا هو سبب وجودها أمام جلالتك، فهي تخرج من شفتيك.. أنت الت تحكم البلاد في عدل).

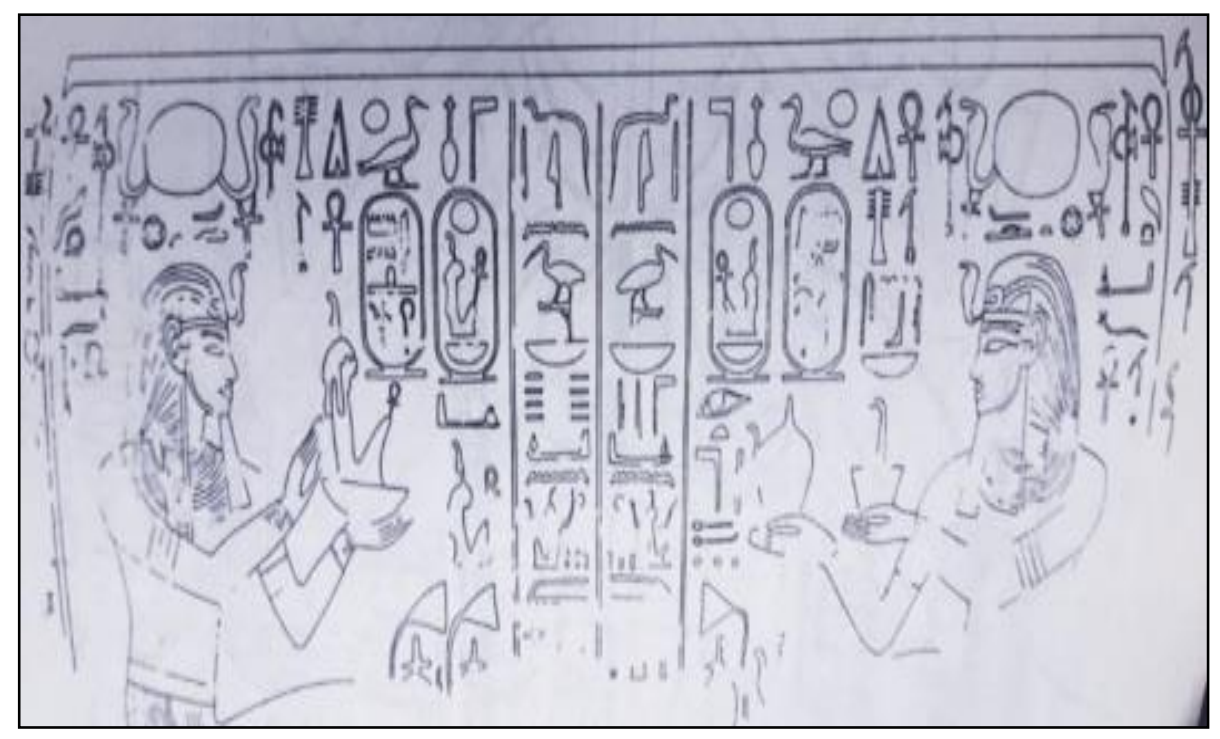

نقش للملك امنحوتب الثالث بالواجهة الثرقية لمعبد تحوت بالأشمونين.

نقلاً عن: Spencer, Bailey and Burnett, Ashmunein, London, 1982, p 84, fig 22

' يان اسمان، ماعت مصر الفرعونية وفكرة العدالة الاجتماعية، ترجمة زكية طبوزاده، دار الفكر للار اسات والنشر،

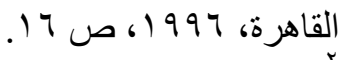
Miriam Lichtheim: Maat in Egyptian Autobiographies and Related studies, London, p.49.- ${ }^{r}$

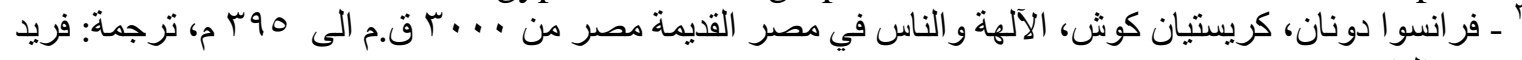

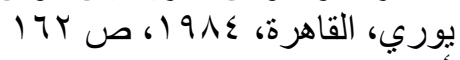
$\mathrm{Wb}, 11,12,23$. -

S. Morenz; Agypteische Religon, Stutgart,1960,p 120. -

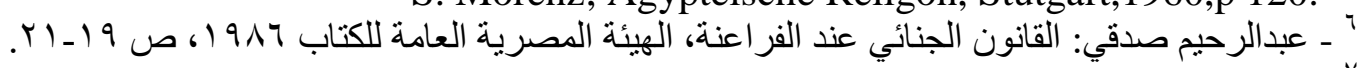
S. Wilson. J.A: A Hymn to Amon-Re, Ancient Near East Textslondon.1969.p.190. - 